\title{
Biochemical and Immunologic Analysis of Hereditary
} Myeloperoxidase Deficiency

\author{
William M. Nauseef, Richard K. Root, and Harry L. Malech, \\ Department of Medicine, Yale University School of Medicine, \\ New Haven, Connecticut 06510
}

\begin{abstract}
A B S T R A C T Myeloperoxidase (MPO), a heme enzyme present in the azurophilic granules of human polymorphonuclear neutrophils (PMN), is important in the oxygen-dependent microbicidal activity of PMN. MPO deficiency, defined as the lack of PMN peroxidative activity, is a common genetic defect of human PMN. The purpose of our study was to characterize the structural basis for this loss of enzymatic activity, using protein biochemical and immunochemical techniques to examine PMN from three subjects with partial MPO deficiency and from five subjects with complete MPO deficiency.
\end{abstract}

We purified MPO from normal PMN and defined its electrophoretic mobility after two-dimensional electrophoretic separation, using nondenaturing acidic polyacrylamide gel electrophoresis (PAGE) followed by sodium dodecyl sulfate (SDS) denaturation and SDS-PAGE separation of MPO subunit peptides. In agreement with previous studies, we found that normal MPO had subunits of 59,000 and 13,500 mol wt when subjected to SDS-PAGE under reducing conditions.

Granule protein extracts of normal PMN, partially MPO-deficient PMN, and completely MPO-deficient PMN were analyzed with two-dimensional PAGE. Partially MPO-deficient PMN granules contained electrophoretically normal MPO in less than normal amounts, whereas completely MPO-deficient PMN granules contain no protein with the electrophoretic mobility of normal MPO.

Using rabbit antiserum against purified MPO, we used immunoautoradiographic analysis to examine whole PMN for peptides immunochemically related to MPO. PMN from normal, partially MPO-deficient, and completely MPO-deficient subjects were solubi-

Portions of this work were presented at the American Federation for Clinical Research National Meeting, May 1981, San Francisco, CA.

Address reprint requests to Dr. Malech.

Received for publication 23 April 1982 and in revised form 21 January 1983. lized in SDS and component peptides separated by SDS-PAGE. The peptides were electroblotted onto nitrocellulose paper that was exposed sequentially to rabbit anti-MPO and ${ }^{125} \mathrm{I}$-protein $\mathrm{A}$ before autoradiography. Radiolabeled bands were identical when partially purified MPO or normal PMN were compared except that whole PMN contained a small amount of an immunologically cross-reactive membrane associated material of 75,000-90,000 mol wt. Using a modification of this immunoautoradiographic analysis, we quantitated the relative amounts of MPO peptides in PMN. PMN from MPO-deficient subjects contain $41.0-52.3 \%$ the amount of MPO peptides present in normal PMN. Similar analysis showed that completely MPO-deficient PMN lacked any peptides corresponding to MPO peptides.

We conclude that partial MPO deficiency is characterized by the presence of electrophoretically and immunologically normal MPO in amounts approximately one-half that seen in PMN from normal subjects. Completely MPO-deficient PMN lack any normal MPO peptides. No MPO-deficient subject studied had an immunologically cross-reacting variant of MPO. Since this deficiency is associated with the absence of more than one peptide, it is possible that the underlying genetic defect may involve: $(a)$ failure to synthesize a single precursor peptide; (b) abnormal regulation of the synthesis of two separate peptides; or $(c)$ an aberration in postsynthetic processing or packaging into azurophilic granules.

\section{INTRODUCTION}

Myeloperoxidase (MPO) ${ }^{1}$ is a heme enzyme that comprises $2-4 \%$ of the polymorphonuclear leukocyte (PMN)

\footnotetext{
${ }^{1}$ Abbreviations used in this paper: $\mathrm{A}_{430} / \mathrm{A}_{280}$, ratio of the absorbance of light at $430 \mathrm{~nm}$. to that at $280 \mathrm{~nm}$.; DFP diisopropylfluorophosphate; MPO, myeloperoxidase; PAGE, polyacrylamide gel electrophoresis; PMN, polymorphonuclear leukocyte.
} 
by weight and is present in smaller amounts in monocytes (1). When stimulated the PMN consumes oxygen and produces superoxide anion, hydrogen peroxide $\left(\mathrm{H}_{2} \mathrm{O}_{2}\right)$, and other toxic oxygen species. Klebanoff and others first described the enhanced microbicidal activity of $\mathrm{H}_{2} \mathrm{O}_{2}$ and a halide in the presence of MPO (2-5). MPO catalyzes the production of hypohalous acids, primarily hypochlorous acid in physiologic situations, and other toxic intermediates that greatly enhance PMN microbicidal activity (6).

Several studies over the past twenty years have described subjects whose PMN lack MPO activity (7-17). Although MPO deficiency is occasionally an acquired defect associated with another hematologic abnormality (18-21), primary MPO deficiency is the form more commonly reported. Until recently primary MPO deficiency appeared to be a rare entity, with only 15 cases in the literature (7-14). Recently, using automated flow cytochemistry, we reported the prevalence of primary MPO deficiency to be one in several thousand (16). Earlier studies suggested that MPO deficiency is an autosomal recessive genetic defect (7-9); however our more recent studies demonstrated that expression of the defect by family members was quite variable and this finding has been supported by other studies $(14,15)$.

Although in vitro evidence suggests an important role for MPO in PMN microbicidal activity and recent epidemiologic data indicate that MPO deficiency is relatively common, most people with MPO deficiency are healthy, suffering neither frequent nor severe infections. A few cases of visceral candida infections in subjects with MPO deficiency have been reported (9, $11,14,16)$, and in vitro studies of microbicidal activity of MPO-deficient PMN have demonstrated a profound defect in candidacidal activity with only a mild impairment of the ability to kill bacteria $(9,11,15$, 16, 22).

Agner first isolated MPO from PMN in 1941 (23) and since that time, the observations of Klebanoff and others of the biologic importance of MPO in human host defenses have stimulated further investigation into the structure of the enzyme (for review see reference 1). Recent evidence indicates that MPO is a glycoprotein with a molecular weight of $\sim 150,000$. Andrews and Krinsky suggested that MPO is composed of two heavy-light protomers, each containing a heavy subunit of $57,000 \mathrm{~mol}$ wt and a light subunit 14,000 mol wt (24). Each of the heavy subunits coordinates with an iron-containing heme group giving MPO its characteristic bright green color as a result of its peak light absorbance at a wavelength of $430 \mathrm{~nm}$. In this model the two heavy-light protomers are linked along their long axes by a single disulfide bond between the two heavy subunits. This bond can be broken by reduction producing "hemi-myeloperoxidase." These two halves of myeloperoxidase retain the full specific activity of native MPO, suggesting that peroxidative activity is not primarily dependent upon interaction between the heme groups of the two protomers in the native enzyme.

MPO deficiency has been defined as the lack of MPO peroxidative activity in PMN and monocytes. The complex pattern of inheritance of MPO deficiency, the fact that MPO is composed of at least two distinct peptides, and the requirement of the iron-containing heme group for maximal enzyme activity raised the possibilities that MPO deficiency might represent synthesis of an aberrant enzyme, loss of the heme group from the enzyme, failure to synthesize one of the two MPO peptides, or the complete absence of any MPO peptide. Our earlier observations that MPO-deficient PMN varied in their ability to iodinate protein, a function believed to be mediated by MPO, and that MPOdeficient PMN had residual peroxidase activity when assessed by the oxidation of $o$-tolidine (16) further supported these possibilities. Salmon et al. (10) used antiserum to MPO in immunofluorescence studies to examine leukocytes from a single subject with MPO deficiency. Neither PMN nor monocytes from that subject appeared to bind the antiserum. However, the presence of small amounts of MPO cannot be excluded by such fluorescence studies.

Our recent identification of many subjects with complete or partial MPO deficiency has allowed us to examine the biochemical nature of the defect in a large group of unrelated subjects. We analyzed the proteins from PMN of five subjects with complete MPO deficiency and three subjects with partial MPO deficiency. Light absorbance at $430 \mathrm{~nm}$, patterns of peptide migration after polyacrylamide gel electrophoresis (PAGE), and results of immunoautoradiographic analysis demonstrated clearly that complete MPO deficiency is associated with the absence of any MPO peptides in the PMN, whereas partial deficiency is associated with the presence of decreased amounts of normal MPO.

\section{METHODS}

Subjects with MPO deficiency. We studied five subjects whose PMN lacked detectable peroxidase activity and three subjects whose PMN had less than normal peroxidase activity. All but one of the individuals studied were among the 29 subjects with MPO deficiency whom we reported earlier (16). An additional individual presented in this study had complete deficiency of MPO and was identified by Dr. Parry subsequent to publication of the original study. The techniques used to identify subjects with MPO deficiency and the additional studies employed to quantitate enzymatic activity were outlined in our original report. 
The eight subjects in our present study were unrelated adults 16 to $48 \mathrm{yr}$ of age, three male and five female. At the time of study no subject was clinically ill. No subject had evidence of increased susceptibility to infection, although one male with partial MPO deficiency had had Bacteroides fragilis and Streptococcus bovis bacteremia complicating a para-appendiceal abscess.

Cell preparation. PMN were purified from fresh heparinized venous blood obtained from subjects with MPO deficiency and from normal volunteers. Venous blood was subjected to Ficoll-hypaque density gradient centrifugation followed by $3 \%$ dextran sedimentation and hypotonic lysis of erythrocytes, yielding cell preparations that were 9097\% PMN.

The large numbers of normal PMN needed for the preparation of purified MPO were obtained by $3 \%$ dextran sedimentation of granulocyte packs prepared for transfusion by batch centrifugation with hydroxyethyl starch (25) and had outdated no $>24 \mathrm{~h}$ before our procuring them. A typical preparation yielded more than $6 \times 10^{9} \mathrm{PMN}$ at $>90 \%$ purity.

Purification of MPO. PMN isolated as described above were suspended in Hanks' balanced salt solution (HBSS) at $2.5 \times 10^{6} \mathrm{PMN} / \mathrm{ml}$ and exposed to $1 \mathrm{mM}$ diisopropyl fluorophosphate (DFP) at $0^{\circ} \mathrm{C}$ for $1 \mathrm{~h}$ to inhibit the activity of PMN proteases (26). PMN were pelleted, resuspended at 2 $\times 10^{7} \mathrm{PMN} / \mathrm{ml}$ in modified Hanks' salt solution without calcium but containing $2.5 \mathrm{mM} \mathrm{MgCl}$, placed in a pressure homogenizer (Parr Instrument Co., Molline, IL), and equilibrated for $45 \mathrm{~min}$ with $\mathrm{N}_{2}$ at $750 \mathrm{psi}$, a modification of the technique described by Klempner et al. (27). The vessel was agitated well before the pressurized cell suspension was very slowly released and the homogenate collected drop-wise in a flask containing a volume of modified Hanks' salt solution with $5.0 \mathrm{mM}$ EDTA and $2 \mathrm{mM}$ DFP equal to the original cell suspension. This procedure resulted in $80-95 \%$ cell breakage and appeared to leave most nuclei intact. Intact cells, nuclei, and other larger pieces of cellular debris were removed by centrifugation at $1,800 \mathrm{~g}$ for $10 \mathrm{~min}$. A dark green granule-rich pellet was then obtained by centrifugation of the supernate at $12,000 \mathrm{~g}$ for $30 \mathrm{~min}$. This material was stored as a pellet in liquid nitrogen until further processing with no loss of peroxidase activity.

The thawed granules were suspended in $0.02 \mathrm{M} \mathrm{K}_{3} \mathrm{PO}_{4}$ (pH 7.4) containing $0.5 \%$ cetyltrimethylammonium bromide (Sigma Chemical Co., St. Louis, MO) and sonicated at $75 \mathrm{~W}$ (Branson Sonic Power, Danbury, C1) for $2 \mathrm{~min}$ at $0^{\circ} \mathrm{C}$. Insoluble material was pelleted from the preparation by centrifugation at $12,000 \mathrm{~g}$ for $10 \mathrm{~min}$ and the solubilized granule proteins were dialyzed overnight at $40^{\circ} \mathrm{C}$ in $0.02 \mathrm{M} \mathrm{K}_{3} \mathrm{PO}_{4}$ (pH 7.4). After the white precipitate that formed during dialysis was removed by centrifugation, the bright green granule protein extract was lyophilized overnight to reduce the volume. The lyophilized material was solubilized in $\mathbf{0 . 2}$ to $0.5 \mathrm{ml}$ of column buffer $(0.13 \mathrm{M} \mathrm{NaCl}, 0.02 \mathrm{M} \mathrm{Na}$ acetate, $0.5 \% \beta$-mercaptoethanol, $\mathrm{pH} 5.0$ ) and applied to a $1 \times 90$ cm Sephadex G-150 column, and eluted with column buffer. Green fractions were assayed for purity by determining the ratio of light absorbance at $430 \mathrm{~nm}$ (the Soret band for the heme group of native MPO) to that at $280 \mathrm{~nm}$ (an estimate of protein concentration). A solution of pure MPO at $1 \mathrm{mg} /$ $\mathrm{ml}$ has an A430/A280 between 0.81 and 0.83 (28). Fractions from the G-150 column having the highest A430 also had the highest A430/A280, between 0.75 and 0.79 , and the greatest peroxidase activity, measured spectrophotometrically using 4-aminoantipyrine (Sigma Chemical Co.) as the chromogen (see below). Analysis of column fractions by SDSPAGE showed that those with the highest A430/A280 and peroxidase activity contained primarily MPO peptides and a small amount of a contaminant of $\sim 81,000 \mathrm{~mol}$ wt.

These fractions with the highest A430/A280 were pooled lyophilized, dissolved in $0.2 \mathrm{ml}$ of column buffer and applied to the same Sephadex G-150 column. Fractions were eluted with the same column buffer and the green fractions containing the highest concentration of MPO as determined by A430 measurements had an A430/A280 of 0.80-0.82 and appeared to be pure MPO by SDS-PAGE. This pure material was used as the immunogen in rabbits to raise antiserum against MPO. Because this purification procedure involved substantial loss of MPO between the first and second runs on the Sephadex G150 column, we used the partially pure MPO from the first column in a number of studies in which MPO was needed as a control in enzymatic analyses or where MPO was needed as a marker in PAGE analysis. The 81,000mol wt peptide lacked peroxidase activity and did not adversely affect the stability of pure MPO. We will refer to this material as "partially purified MPO" and to that material eluted from the second column as "pure MPO."

Preparation of granule protein extracts. MPO-enriched granule protein extracts were prepared from the smaller number of PMN available from normal donors and MPOdeficient subjects using a modification of the procedure used in the purification of MPO from granulocyte transfusions. $\mathrm{PMN}$ at 1 to $2 \times 10^{8} \mathrm{PMN} / \mathrm{ml}$ suspended in $0.34 \mathrm{M}$ sucrose at $0^{\circ} \mathrm{C}$ were homogenized with a Potter-Elvehjem homogenizer (J. T. Baker Co., Phillipsburg, NJ) at 6,000 rpm for several 2 -min intervals until cell breakage was estimated at $>90 \%$ by phase microscopy. The homogenate was centrifuged at $1,800 \mathrm{~g}$ for $10 \mathrm{~min}$ and the supernate centrifuged at $12,000 \mathrm{~g}$ for $30 \mathrm{~min}$ to obtain a granule pellet that was stored in liquid nitrogen.

The thawed granules were suspended in $0.02 \mathrm{M} \mathrm{K}_{3} \mathrm{PO}_{4}$ (pH 7.4) with $0.5 \%$ cetyltrimethylammonium bromide, sonicated, and centrifuged. As described in the previous section the supernate was dialyzed overnight in $0.02 \mathrm{M} \mathrm{K}_{3} \mathrm{PO}_{4}$ and the white precipitate that formed was removed by centrifugation. The supernate was further enriched for MPO by differential precipitation with ammonium sulfate $\left[\left(\mathrm{NH}_{4}\right)_{2} \mathrm{SO}_{4}\right]$ using a modification of the technique of Bakkenist (29). Proteins precipitating at $50 \%$ saturation with $\left(\mathrm{NH}_{4}\right)_{2} \mathrm{SO}_{4}$ were discarded and the precipitate formed between $50 \%$ and $72 \%\left(\mathrm{NH}_{4}\right)_{2} \mathrm{SO}_{4}$ saturation was collected, the $\mathrm{pH}$ maintained at 7.3 throughout the precipitation using 1 $\mathrm{M} \mathrm{K}_{2} \mathrm{HPO}_{4}$. The precipitate was dissolved in $100 \mathrm{mM}$ sodium acetate (pH 4.9) and again subjected to differential salt precipitation. The fraction precipitating between 50 and $65 \%$ $\left(\mathrm{NH}_{4}\right)_{2} \mathrm{SO}_{4}$ was collected, dissolved in a small volume of 100 $\mathrm{mM} \mathrm{K} \mathrm{PO}_{4}$ ( $\mathrm{pH} 7.4$ ), and dialyzed overnight in the same buffer at $4^{\circ} \mathrm{C}$

When normal PMN were used as starting material, the initial extract of PMN granules had a specific activity for peroxidase of $10.2 \mathrm{U} / \mathrm{mg}$ protein, whereas the final dialysate had a specific activity of $30.7 \mathrm{U} / \mathrm{mg}$ protein, suggesting a threefold enrichment in MPO had been obtained. We will refer to this material as "MPO-enriched granule protein extract."

Preparation of antiserum to MPO. Pure MPO was mixed with complete Freund's adjuvant and injected subcutaneously into a New Zealand white rabbit. Repeated injections at 2 -wk intervals were continued for $10 \mathrm{wk}$, at which time serum from the immunized rabbit was found to form a single 
immunoprecipitation band with partially purified MPO as determined in an Ouchterlony immunodiffusion assay. The antiserum was used without further preparation.

PAGE. To analyze MPO or the proteins in the MPOenriched granule protein extract, we separated the protein components using two-dimensional PAGE performed in the following way.

Pure MPO or MPO-enriched granule protein extract was mixed with a one-tenth volume of running buffer $(0.35 \mathrm{M}$ $\beta$-alanine $0.14 \mathrm{M}$ acetic acid, $\mathrm{pH}$ 5.0) and electrophoresed under nondenaturing conditions into acidic $7.5 \%$ polyacrylamide gels $(0.48 \mathrm{~N} \mathrm{KOH}$ in $2.9 \mathrm{M}$ acetic acid, $\mathrm{pH} 4.3)$ in hollow glass tubes ( $3 \mathrm{~mm}$ internal diam) following a modification of the technique of disc electrophoresis described by Reisfeld et al. (30). The gels were run at constant current $(6.0 \mathrm{~mA} / \mathrm{gel})$ until the dye front (basic fuchsin) reached 10.5 cm migrating toward the cathode.

With the granule proteins still in their native state and separated along the length of the acidic gel, the gel was removed from the glass tube and soaked in $10 \mathrm{ml}$ of SDS solubilizing buffer (6\% SDS, $4 \mathrm{M}$ urea, $125 \mathrm{mM}$ Tris-salt, 4 mM EDTA, at pH 6.9) with $10 \% \beta$-mercaptoethanol at room temperature for $45 \mathrm{~min}$ to denature and reduce the native proteins into their component peptides and to raise the $\mathrm{pH}$ of the acidic gel. This gel was then placed across the top of a 10 or $15 \%$ polyacrylamide slab gel with $3.5 \%$ stacking gel prepared according to the method of Laemmli (31) but containing $0.2 \%$ SDS. This electrophoresis was performed at 30 $\mathrm{V}$ constant voltage overnight after which the voltage was increased to $100 \mathrm{~V}$ until the bromphenol blue tracking dye reached $10.5 \mathrm{~cm}$ from the origin migrating toward the anode. In this way the cationic proteins in the MPO-enriched granule protein extract were separated first in their native state on the basis of size and charge at acidic $\mathrm{pH}$, followed by separation of the individual peptides according to molecular weight in the slab gel. The slab gels were fixed and stained with Coomassie Brilliant Blue in acetic acid-methanol, followed by destaining in aqueous acetic acidmethanol.

In other studies whole PMN, granule protein extract, purified MPO, or various protein molecular weight standards were solubilized in SDS solubilizing buffer, heated at $90^{\circ} \mathrm{C}$ for $2 \mathrm{~min}$, and directly electrophoresed into $0.2 \%$ SDS, $10 \%$ or $13 \%$ polyacrylamide slab gels with stacking gels of $3.5 \%$ polyacrylamide (31). Although PMN solubilized in the SDS solubilizing buffer formed a very viscous solution that was difficult to place into wells in the stacking gel, proteins in the viscous solution appeared to electrophorese normally into the polyacrylamide slab gel

The molecular weights of MPO or other peptides as described in the results were extrapolated from molecular weight curves determined by SDS-PAGE analysis of a large number of protein standards of known molecular weight. Molecular weights of peptides from 25,000 to 120,000 were determined in $10 \%$ polyacrylamide slab gels, where the relationship between the distance migrated into the gel and the molecular weight is linear when plotted semilogarithmically. Molecular weight determination of peptides of 6,000 to 25,000 were obtained on 13 or $15 \%$ polyacrylamide slab gels. In some instances we used SDS-PAGE analysis with $10 \%$ polyacrylamide gels to achieve better resolution of higher molecular weight peptides. In such $10 \%$ gels, the lower molecular weight component of MPO migrated with the dye front where molecular weight determination is not possible. Where a molecular weight is indicated in such an instance, the molecular weight was determined in a higher percent acrylamide gel and no material of lower molecular weight was detected.

Immunoautoradiographic detection of MPO peptides. After separation of PMN proteins by SDS-PAGE, the banding pattern was transferred electrophoretically from the gel to nitrocellulose paper according to the technique of Towbin et al. (32). A sheet of nitrocellulose paper was placed on one side of the slab gel and this gel and paper placed in the transfer apparatus. The transfer was performed in an apparatus in which electrical current is passed perpendicular to the plane of the gel, thus transferring some of the protein from the gel to the nitrocellulose paper, where the protein adheres electrostatically. The buffer used for this procedure was Tris-glycine aqueous methanol $(0.025 \mathrm{M}$ Tris base, 0.192 $\mathrm{M}$ glycine, $20 \%$ methanol, $\mathrm{pH} 8.3$ ) and the electrophoresis was run at constant voltage, $35 \mathrm{~V}$ for $1.75 \mathrm{~h}$. Some of the protein remained in the gel, which was then stained with Coomassie Brilliant Blue and destained in the usual fashion.

The nitrocellulose paper was placed in $50 \mathrm{ml}$ of Burridge buffer $\left(50 \mathrm{mM}\right.$ Tris base, $150 \mathrm{mM} \mathrm{NaCl}, 0.005 \% \mathrm{NaN}_{3}$ at $\mathrm{pH}$ 8.7) containing $3 \%$ bovine serum albumin (BSA, radioimmunoassay grade, Sigma Chemical Co.) overnight. The paper was then placed in rabbit anti-MPO serum or preimmune rabbit serum (diluted 1:40) in 3\% BSA in Burridge buffer for $2 \mathrm{~h}$ at room temperature. The paper was extensively washed over $1 \mathrm{~h}$ with multiple changes of Burridge buffer and then placed in $50 \mathrm{ml}$ of Burridge buffer containing $3 \%$ BSA and ${ }^{125}$ I-protein A (1 to $3 \times 10^{5} \mathrm{cpm} / \mathrm{ml}$ provided by Dr. V. T. Andriole, Ýale University) for $1 \mathrm{~h}$ at room temperature. The paper was extensively washed over several hours with multiple changes of Burridge buffer, left overnight in the same buffer, and again washed well the next morning. The paper was dried and autoradiographed using Kodak XAR-5 x-ray film (Eastman Kodak Co., Rochester, $\mathrm{NY}$ ) and a fluorescence intensifying screen

Immunochemical quantitation of MPO peptides. We experimentally determined that the electroblot transfer of SDS-PAGE separated peptides from the gel to nitrocellulose paper can be used to quantitate the amount of peptide originally present in the sample loaded on the gel. A range of concentrations of whole PMN from two normal subjects and samples of purified MPO were solubilized in SDS solubilizing buffer and loaded in different lanes of a multilaned $13 \%$ polyacrylamide SDS gel. PAGE was performed in the usual fashion and the peptides transferred electrophoretically to nitrocellulose paper as described. After sequential exposure to anti-MPO and ${ }^{125}$ I-protein A the paper was dried and autoradiographed as described above

The optical densities of the bands on the autoradiograph are not linearly related to the amount of radioactivity on the paper. Therefore, we instead used the autoradiograph as a guide to cut out the areas of the nitrocellulose paper containing each MPO peptide. Pieces of paper corresponding to the MPO subunit peptides at 59,000-,39,000-, 24,000- and $13,500-\mathrm{mol}$ wt were cut out. Control pieces of the paper of size equal to a particular band were cut from an adjacent portion of the paper that did not contain any peptides. The pieces of nitrocellulose paper were counted in a gamma counter. We consistently found that for the 59,000- and 39,000 -mol wt bands there is a linear relationship between counts and the number of cells in the original sample loaded in the range of 2.5 to $10 \times 10^{6} \mathrm{PMN}$. Using this technique it was also possible to quantitate the amount of MPO in the sample when compared to a similarly run sample of a known amount of purified MPO.

Assay of MPO activity. Activity of MPO in the low pH 
gels, where the enzyme was still in its native state, was determined by the technique of Graham and Karnovsky (33).

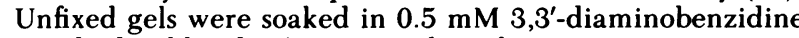
tetrahydrochloride (DAB-4HCl, Polysciences, Inc., Warrington, PA) in $35 \mathrm{mM} \beta$-alanine at $\mathrm{pH} 4.5$ followed by exposure to freshly prepared $3.5 \mathrm{mM} \mathrm{H}_{2} \mathrm{O}_{2}$ for $5 \mathrm{~min}$. Gels were fixed in $12.5 \%$ trichloroacetic acid for $1 \mathrm{~h}$ and stored in $7 \%$ acetic acid.

The peroxidative activity of MPO-enriched granule proteins, partially purified MPO, and pure MPO was measured using 4-aminoantipyrine as the chromagen (Sigma Chemical Co.). In a $3-\mathrm{ml}$ cuvette $1.4 \mathrm{ml}$ of $2.5 \mathrm{mM} \mathrm{4-aminoantipyrine}$ in $170 \mathrm{mM}$ phenol was mixed with $1.5 \mathrm{ml}$ of $1.7 \mathrm{mM} \mathrm{H}_{2} \mathrm{O}_{2}$ (prepared fresh daily) and incubated $3-4 \mathrm{~min}$ at $25^{\circ} \mathrm{C}$. An aliquot of $100 \mu$ l of dilute sample was added and the increase in A510 measured for $5 \mathrm{~min}$. A unit of enzymatic activity was defined as the amount of enzyme that catalyzes the decomposition of $1 \mathrm{mmol}$ of $\mathrm{H}_{2} \mathrm{O}_{2} / \mathrm{min}$ at $25^{\circ} \mathrm{C}$ and $\mathrm{pH} 7.0$ and correlated with a change of $1.0 \mathrm{U}$ of $\mathrm{OD} / \mathrm{min}$ at $510 \mathrm{~nm}$ (34).

Protein determination. Protein concentrations of samples loaded onto gels were determined by the technique of Sedmak and Grossberg (35).

\section{RESULTS}

Electrophoretic pattern of pure MPO. Pooled fractions of highly purified MPO obtained after separation over the G150 Sephadex column were green in color and had an A430/A280 of 0.81. Fig. 1 shows the SDS-

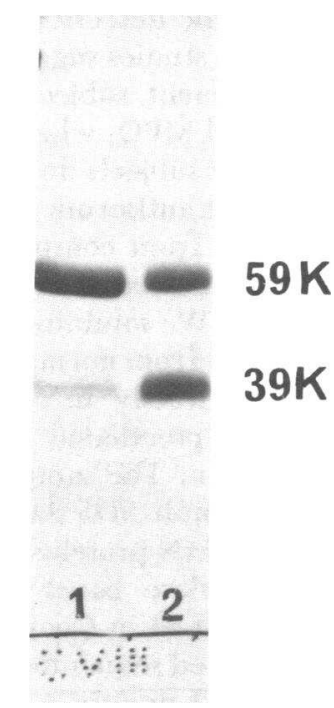

FIGURE 1 SDS-PAGE analysis of purified MPO. Samples of pure MPO were denatured in SDS-buffer either containing $10 \% \beta$-mercaptoethanol (lane 1) or without the reducing agent (lane 2). After reduction and exposure to SDS, the high molecular weight subunit of MPO migrates primarily at an apparent $59,000 \mathrm{~mol} w \mathrm{w}$, while a lesser amount migrates at $39,000 \mathrm{~mol} w \mathrm{w}$. The low $13,500-\mathrm{mol}$ wt subunit of MPO migrates with the dye front in this $10 \%$ acrylamide gel. Without reduction equal amounts of the high molecular weight subunit of MPO appear to migrate at 59,000 and $39,000 \mathrm{~mol}$ wt.
PAGE pattern of pure MPO that was heated in SDS solubilizing buffer with (lane 1) and without (lane 2) a reducing agent (10\% $\beta$-mercaptoethanol). Under reducing conditions pure MPO appears to be composed of a 59,000-mol wt peptide, a $13,500-\mathrm{mol}$ wt peptide, which migrates at the dye front in the $10 \%$ polyacrylamide gel, and a very small amount of a 39,000-mol wt peptide. Under non-reducing conditions approximately one-half of the 59,000 -mol wt peptide electrophoreses with an apparent molecular weight of 39,000. This phenomenon has been noted in some earlier studies and postulated to reflect the presence of an intrapeptide disulfide band that decreases the average radius of the otherwise SDS-denatured peptide (34).

In other studies pure MPO was electrophoresed under nondenaturing conditions into acidic tube gels as described in Methods. Pure MPO migrates as a broad though apparently single green band located $\sim 0.75$ of the distance from the origin to the basic fuchsin dye front (not shown). When this gel was fixed and stained with Coomassie Brilliant Blue, a single broad blue band of protein could be seen corresponding to the green band in the unstained gel. This same band also demonstrated peroxidase activity when exposed to $\mathrm{H}_{2} \mathrm{O}_{2}$ and DAB-4HCl (not shown).

An identical acidic tube gel into which nondenatured MPO was electrophoresed was soaked in SDS solubilizing buffer containing $10 \% \beta$-mercaptoethanol for $45 \mathrm{~min}$ and placed horizontally atop a $15 \%$ polyacrylamide slab gel containing SDS, as described for two-dimensional PAGE analysis in Methods. The peptides of MPO in the tube gel denatured by SDS and reduced by $\beta$-mercaptoethanol, were electrophoresed into the slab gel producing the pattern seen in Fig. 2 . The single green band of MPO is shown in Fig. 2 to be composed of the $59,000-\mathrm{mol}$ wt peptide and a broad 13,500-mol wt peptide.

Analysis of MPO-enriched granule protein extracts. Granules and MPO-enriched granule protein extracts from the PMN of normal subjects were green and the MPO-enriched granule protein extracts had an A430/A280 of 0.30 to 0.40. Granules and MPOenriched granule protein extracts from equivalent numbers of PMN from partially MPO-deficient subjects were less green than those of normal PMN and the MPO-enriched granule protein extract had an A430/A280 of 0.10 to 0.20 . Granules and granule protein extracts from equivalent numbers of PMN from completely MPO-deficient subjects were not green and the granule protein extracts had no light absorption at $430 \mathrm{~nm}$.

Using two-dimensional SDS-PAGE we analyzed the MPO-enriched granule protein extracts from the PMN of several normal subjects and from the PMN of three 


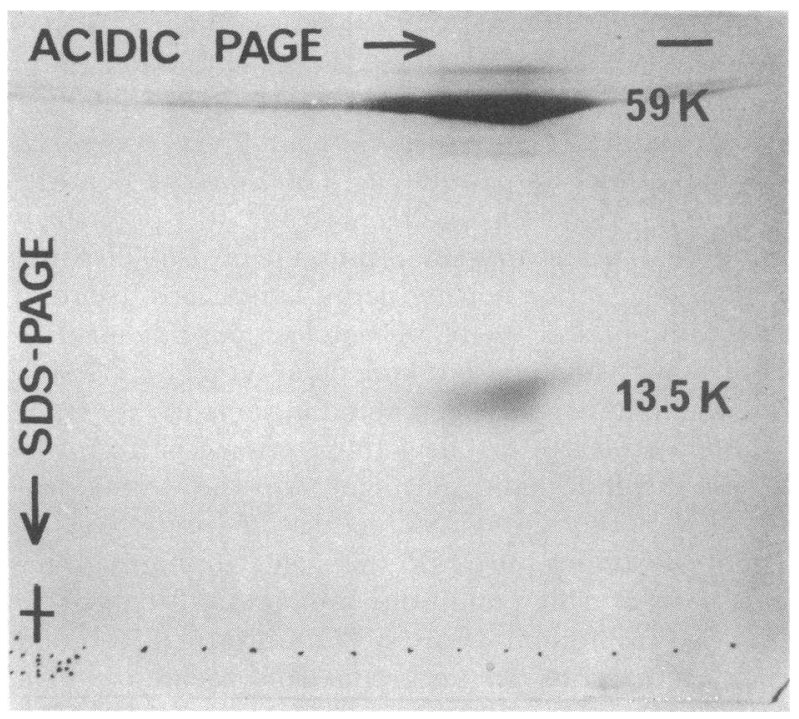

FIGURE 2 Analysis of pure MPO by two-dimensional PAGE. MPO was electrophoresed under nondenaturing conditions into an acidic tube gel migrating toward the cathode. After nondenaturing PAGE, the acidic tube gel was soaked in SDS buffer containing $10 \% \beta$-mercaptoethanol, placed horizontally atop a $15 \%$ acrylamide slab gel, and electrophoresed. Pure MPO migrates towards the cathode as a single broad band under nondenaturing conditions. After reduction and denaturation this protein band is composed of 59,000- and 13,500-mol wt peptides.

partially MPO-deficient subjects. We used the same technique to analyze granule protein extracts from PMN of five MPO-deficient subjects. The results of these two-dimensional analyses (nondenaturing acidic PAGE $\times$ SDS-PAGE) are shown in Fig. 3.

Fig. 3a shows such an analysis of pure MPO and clearly establishes the location to which the 59,000mol wt peptide of MPO migrates under the conditions described. We used a $10 \%$ acrylamide gel to resolve more clearly the 59,000-mol wt peptide, knowing that we would not clearly identify the 13,500 -mol wt peptide that migrates with the dye in this system. In addition, when granule protein extracts are examined in this way (Fig. 3b-d), the location of the 13,500-mol wt peptide is obscured by other proteins migrating to that area in the second dimension slab gel. By virtue of the analysis used, the $13,500-\mathrm{mol}$ wt peptide can be inferred to be present if the 59,000 -mol wt peptide is found at its expected location on the two-dimensional gel.

Two-dimensional PAGE of the MPO-enriched granule extract from normal PMN is shown in Fig. 3b. A prominent $59,000-\mathrm{mol} w \mathrm{wt}$ peptide is present at the position in this gel identical to that to which the $59,000-$ mol wt peptide of pure MPO migrated in Fig. 3a. Analysis of similarly processed extracts from the PMN of other normal subjects always resulted in a prominent 59,000-mol wt peptide. However, varying amounts of the unidentified granule proteins were seen with different preparations of MPO-enriched granule extracts. For each of the partially MPO-deficient subjects, analysis of MPO-enriched granule extracts from their PMN resulted in the pattern shown in Fig. 3c. A 59,000-mol wt peptide was always found at the expected position in the gel. Although the intensity of this band relative to the other unidentified peptides in the gel varied among subjects, the 59,000-mol wt peptide band was always less intense than that from normal PMN. Quantitation of the amount of this peptide present in partially MPO-deficient PMN was determined in other studies using an immunochemical analysis (see below).

Granule protein extracts of PMN from each of the five completely MPO-deficient subjects were similarly processed to isolate any normal MPO present and then subjected to the same two-dimensional PAGE. In each case this resulted in a pattern similar to that shown in Fig. 3d. There was a conspicuous absence of the 59,000 -mol wt MPO peptide in every case (see arrow in Fig. 3d), although all of the usually present unidentified peptides were seen.

Immunoautoradiographic detection of MPO peptides in PMN. The above studies suggested that PMN from partially MPO-deficient subjects possess some electrophoretically normal MPO, whereas PMN from completely MPO-deficient subjects do not contain any normal MPO. Using rabbit antiserum directed against MPO, we analyzed PMN from completely MPO-deficient subjects for the presence of any proteins that react with this antiserum. We solubilized partially purified MPO or whole PMN from normal or completely MPO-deficient subjects directly in SDS solubilizing buffer with $10 \% \beta$-mercaptoethanol and heated the solution to $90^{\circ} \mathrm{C}$ for $4 \mathrm{~min}$. The sample was electrophoresed into $13 \%$ acrylamide SDS slab gels. The separated MPO peptides or PMN proteins were then electroblotted onto nitrocellulose paper as outlined in Methods. The gel was stained in Coomassie Blue and the paper processed, exposed sequentially to the rabbit antiserum to MPO and ${ }^{125}$ I-protein A, and autoradiographed. Fig. 4 shows the results of such analysis, the Coomassie Blue-stained gel in Fig. 4a and the autoradiograph in Fig. 4 b.

PMN from several normal donors and from all five completely MPO-deficient subjects were analyzed. The analysis of one normal donor and three of our five completely MPO-deficient subjects is shown in Fig. 4. Partially purified MPO was electrophoresed into lane 1 of the gel shown in Fig. 4. This material was used 

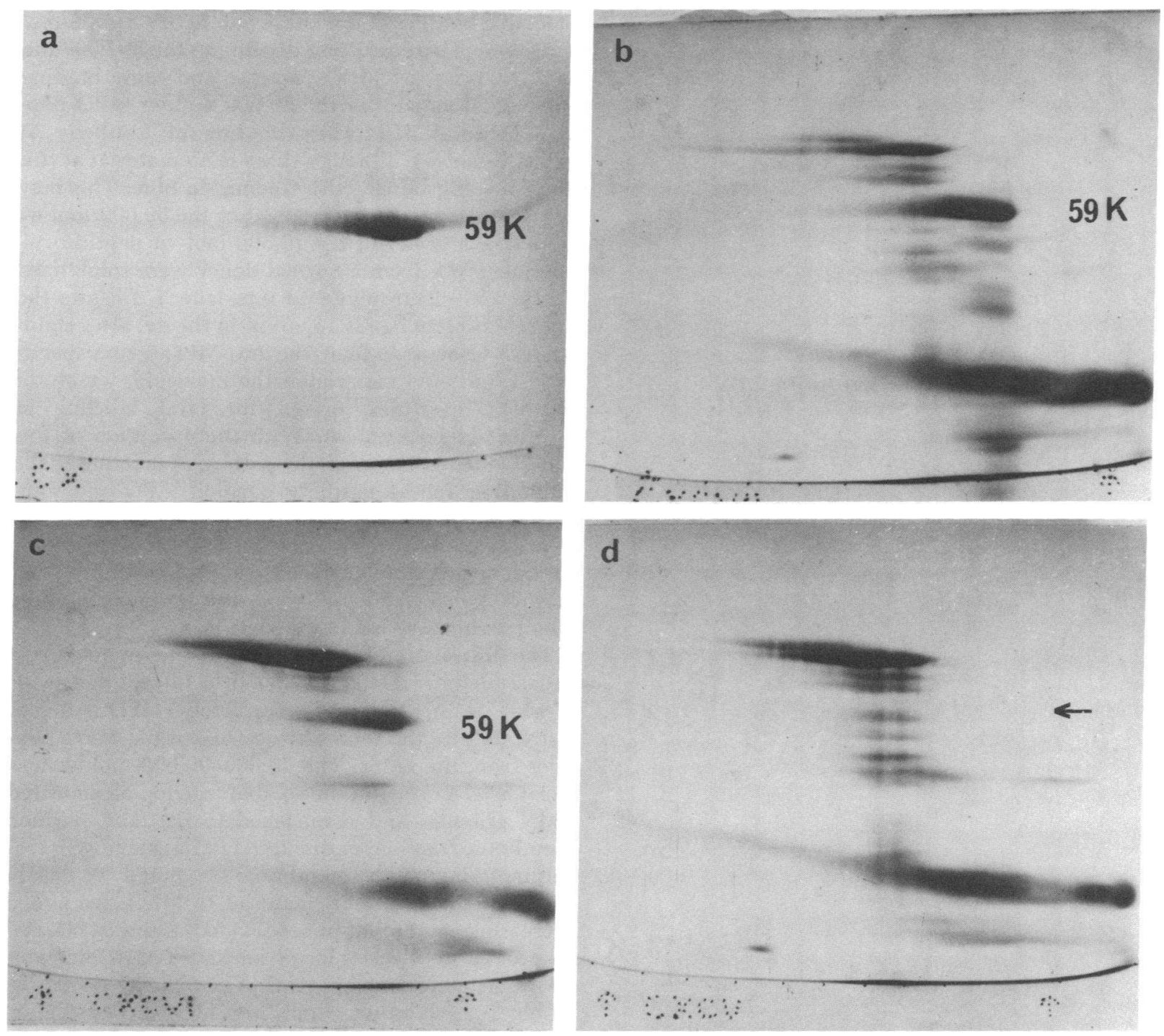

FIGURE 3 Two-dimensional PAGE analysis of pure MPO and of MPO-enriched granule extracts from normal, partially MPO-deficient, and completely MPO-deficient PMN. Pure MPO and PMN granule protein extracts were analyzed as described in Fig. 2 except that the slab gel for SDS-PAGE was $10 \%$ acrylamide. Purified MPO (panel a) has a prominent 59,000-mol wt peptide with the 13,500-mol wt peptide migrating at the dye front. Analysis of MPO-enriched granule protein extracts from normal PMN (panel b) reveals a prominent 59,000-mol wt peptide at the position to which the major subunit of MPO migrates. The same analysis of MPO-enriched granule protein extracts from partially MPO-deficient PMN (panel c) also reveals a 59,000-mol wt peptide that migrates to a position identical to that of the major peptide subunit of pure MPO. However granule protein extracts from completely MPO-deficient PMN have no peptide at the expected position of the 59,000-mol wt peptide (arrow). Unidentified cationic granule peptides were present in similar amounts in all PMN preparations examined.

in place of pure MPO because it contains not only MPO but also an $81,000-m o l$ wt contaminant. This 81,000-mol wt peptide represents the major impurity in our preparation of MPO prior to the final column purification, which yields electrophoretically pure MPO. Despite our use of pure MPO as our immunogen, it was possible that our rabbit antiserum might bind to this contaminant. As shown in Fig. 4, there is no 

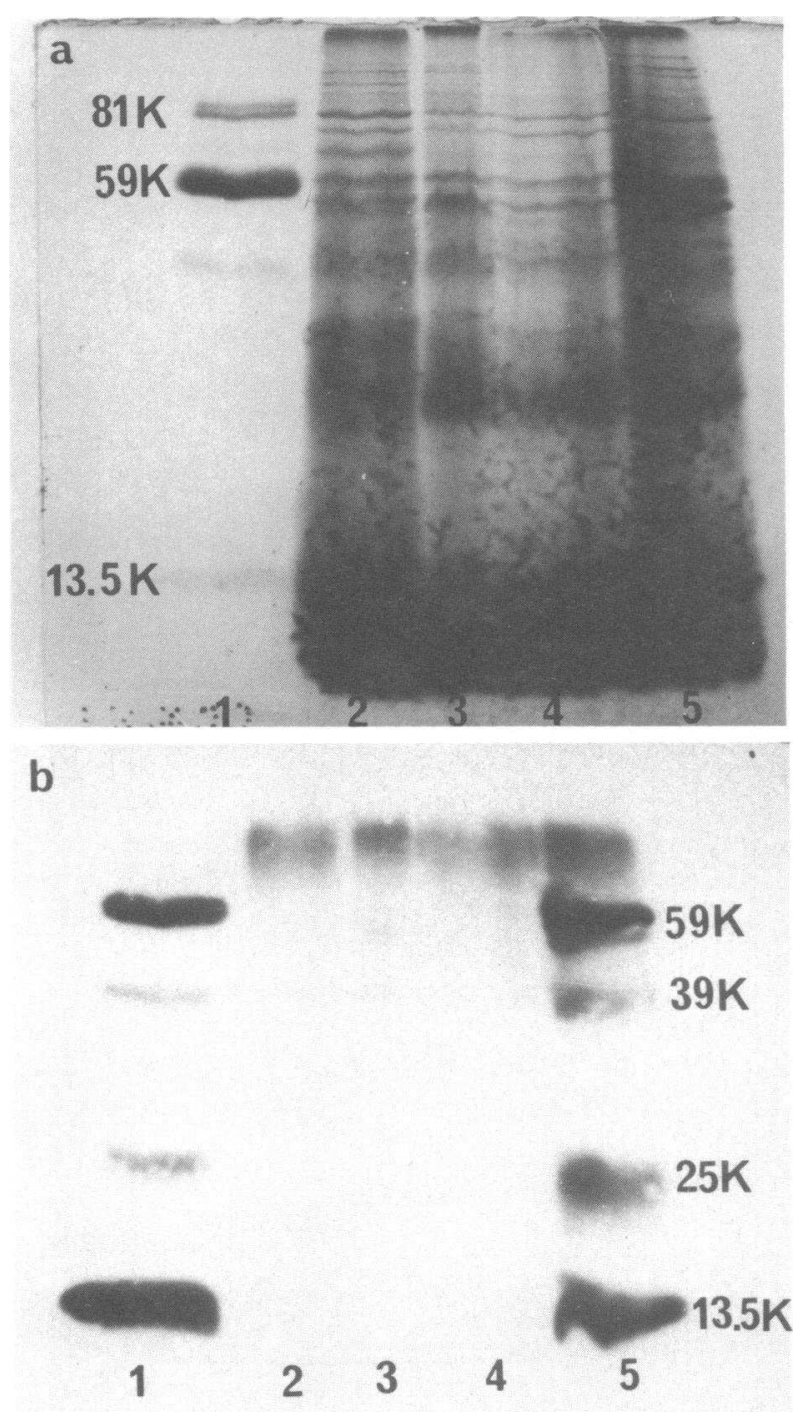

Figure 4 Immunoautoradiographic detection of MPO peptides in whole PMN from normal and MPO-deficient subjects. The Coomassie Blue-stained SDS-PAGE analysis (13\% acrylamide) of partially pure MPO (lane 1), whole PMN from three completely MPO-deficient subjects (lane 2-4), and whole PMN from a normal subject (lane 5) is shown in panel a. Panel $b$ shows the immunoautoradiograph of the same gel using electroblotting of the peptide pattern onto nitrocellulose paper followed by sequential exposure to antiMPO serum and ${ }^{125}$ I-protein A. There is no obvious difference in the peptide patterns of completely MPO-deficient and normal PMN when the gel was stained with Coomassie Brilliant Blue (panel a, lanes 2-5). Anti-MPO serum labeled predominantly the 59,000 - and $13,500-\mathrm{mol}$ wt peptides of MPO (panel b, lane 1), although there is faint labeling at 39,000 and $25,000 \mathrm{~mol}$ wt. Anti-MPO labeled the peptides of normal PMN at the molecular weights corresponding to those of pure MPO (compare panel b, lanes 1 and 5). Completely MPO-deficient PMN (lanes 2-4) did not contain any detectable binding of the antiserum to this $81,000-\mathrm{mol}$ wt peptide. There is strong binding to the 59,000 - and the 13,500-mol wt MPO peptides and some binding to the small amount of the 39,000-mol wt MPO peptide. There is also weak binding of antibody at $\sim 24,000$-mol wt, although there is no material at this site in the gel stained with Coomassie Blue. This may represent a proteolytic fragment of the $59,000-\mathrm{mol}$ wt peptide or a dimer of the 13,500 -mol wt peptide.

Whole PMN from a normal donor were solubilized in SDS and electrophoresed into lane 5. Despite the multiple protein bands apparent in the gel after staining with Coomassie Blue, the anti-MPO serum specifically labels only material at the molecular weight of the MPO peptides, except for faint labeling at $\sim 75,000-90,000$-mol wt. With the exception of this faintly labeling material, the pattern of labeling in the autoradiograph of partially purified MPO and solubilized whole normal PMN is remarkably similar. An identical pattern was seen when PMN from six other normal donors were analyzed using this technique (not shown). No labeled bands were seen when preimmune rabbit serum was used as a control.

The diff use faint binding of antibodies in our rabbit antiserum to material at 75,000 to $90,000-\mathrm{mol}$ wt is present in normal and completely MPO-deficient PMN, despite the total absence of normal MPO peptides from the latter. The 75,000-90,000-mol wt material is never seen in the soluble fraction of sonicated PMN granules and is enriched in partially purified membrane fractions of disrupted PMN, suggesting that this material may be membrane associated. To clarify the relationship of this material to MPO, we added increasing amounts of pure MPO to the anti-MPO used to process an electroblot of an SDS PAGE of whole PMN. As increasing amounts of pure MPO were used to block the binding of anti-MPO to the electroblots, the resultant autoradiographs showed a decrease in binding to both the 59,000-mol wt MPO peptide and the $75,000-90,000-\mathrm{mol}$ wt material.

Whole PMN from three different subjects with complete MPO deficiency were solubilized in SDS solubilizing buffer and electrophoresed into lanes 2, 3, and 4 of the gel shown in Fig. 4. Although there is no obvious difference between normal and completely MPO-deficient PMN in the pattern seen in the gel stained with Coomassie Blue, the corresponding autoradiograph clearly demonstrates that completely MPO-deficient PMN have no material that binds antiMPO at the molecular weight of known MPO peptides

peptides that labeled with anti-MPO (panel b, lanes 2-4) except for material between 75,000 and $90,000 \mathrm{~mol}$ wt, which is cross-reactive material seen in normal PMN as well. 
nor do they have any bands not present in normal PMN. They do, however, contain the 75,000-90,000mol wt material seen in normal PMN.

Immunoautoradiographic quantitation of $M P O$ in MPO-deficient PMN. To measure immunochemically the amount of MPO present in partially and totally MPO-deficient PMN, we adapted the technique of electroblotting. PMN were isolated from two normal subjects (H.M. and W.N.), three partially MPO-deficient subjects (C.N., C.W., J.G.), and one totally MPOdeficient subject (L.H.). Samples of $5 \times 10^{6} \mathrm{PMN}$ from each were subjected to SDS-PAGE and transferred to nitrocellulose paper, which was sequentially exposed to anti-MPO and ${ }^{125}$ I-protein $A$ as described earlier. The autoradiograph obtained was used to define those areas of the nitrocellulose paper to which the 59,000mol wt subunit of MPO was bound.

Data from this analysis are presented in Table I. The 59,000-mol wt peptide from normal PMN transferred to the nitrocellulose paper bound 3,015 and $3,613 \mathrm{cpm}$, respectively (mean $3,314 \mathrm{cpm}$ ). Using the sample of $15.8 \mu \mathrm{g}$ of pure MPO as a standard, PMN from H.M. contained $9.96 \mu \mathrm{g}$ of MPO. Since we determined that a sonicate of $5 \times 10^{6}$ PMN from H.M. has $225 \mu \mathrm{g}$ protein, $4.4 \%$ of the total protein in H.M.'s PMN is MPO, in agreement with prior estimates of 2-5\% (1), thus validating the accuracy of this analysis.

PMN from partially MPO-deficient subjects analyzed in this way have $41.0-52.3 \%$ (mean $45.1 \%$ ) the amount of 59,000-mol wt peptide as do control PMN. PMN from L.H., a totally MPO-deficient subject, have no immunochemical evidence of MPO.

TABLE I

\begin{tabular}{lccc}
\hline \multicolumn{3}{c}{ Immunochemical quantitation of MPO peptides } \\
\hline \multicolumn{1}{c}{ Sample } & Counts & Corrected counts $\downarrow$ & \% Control§ \\
\hline Blank & 2981 & - & - \\
l5 $\mu$ g MPO & 7762 & 4781 & - \\
H.M. & 5996 & 3015 & 91.0 \\
W.N. & 6594 & 3613 & 109.0 \\
C.N. & 4368 & 1387 & 41.9 \\
C.W. & 4715 & 1734 & 52.3 \\
J.G. & 4341 & 1360 & 41.0 \\
L.H. & 2819 & 0 & 0 \\
\hline
\end{tabular}

- Samples are aliquots of $5 \times 10^{6} \mathrm{PMN}$ in Laemmli solubilizing buffer. H.M. and W.N. are normal subjects, whereas C.N., C.W., and J.G. are partially MPO-deficient and L.H. is total MPO-deficient. The average counts per minute for normals is $3,314 \mathrm{cpm}$, while that for partially MPO-deficient subjects is $1,494 \pm 121$.

$\ddagger$ Corrected counts $=$ raw counts - background.

$\S$ Percent control $=\frac{\text { corrected counts }}{\text { Control corrected counts }}$

\section{DISCUSSION}

From our studies of PMN from five unrelated subjects with complete MPO deficiency we conclude that complete MPO deficiency, as defined as the absence of peroxidase activity, is a result of the lack of MPO peptides in PMN. PMN from three subjects with partial MPO deficiency contain electrophoretically normal MPO but in approximately one-half the normal amount, compatible with the decreased level of MPO enzymatic activity in the PMN of these subjects. We find no evidence for the presence of abnormal MPO peptides in the PMN of subjects with either complete or partial MPO deficiency.

Our studies demonstrate that pure MPO is composed of peptide subunits of 59,000 - and $13,500-\mathrm{mol} \mathrm{wt}$, in agreement with some previous reports $(24,36-38)$. We also clearly show that some of the 59,000 -mol wt peptide migrates with an apparent molecular weight of 39,000 in SDS-PAGE under nonreducing conditions.

The nature of the 75,000-90,000-mol wt immunologically cross-reacting peptide found in normal and MPO-deficient PMN and its relationship to the peptides seen' in purified MPO are not clear. The competition binding studies show that purified MPO (which itself does not contain any detectable 75,00090,000-mol wt material) will bind all of the antibodies in the antiserum that cross-react with 75,000-90,000mol wt material. Preliminary evidence suggests that this material is associated with PMN membranes. Whether this material is a non-MPO peptide antigenically related to MPO or whether this represents an MPO precursor cannot be addressed at this time.

Hypotheses explaining the nature of the genetic lesion underlying MPO deficiency must account for the absence of more than one subunit peptide. Certainly our previous family studies (16) suggest that the mode of inheritance is more complicated than a simple autosomal recessive trait. It is possible that MPO deficiency is an example of a regulatory gene defect manifested by the failure of any MPO peptides to be produced, in contrast to the production of aberrant MPO due to a structural gene defect. Alternatively, it is possible that only one of the peptides of MPO is not synthesized and that the remaining peptide(s) is lost from myeloid precursors during subsequent differentiation in bone marrow. Thirdly, it is possible that MPO deficiency involves some postsynthetic defect in which an MPO precursor peptide is normally produced but is not processed correctly or is not packaged into azurophilic granules, with subsequent loss of the MPO peptide(s) during PMN differentiation. Studies presented here do not distinguish among these three hypotheses. A more complete understanding of the nature of this 
relatively common hereditary disorder of $\mathrm{PMN}$ requires more sophisticated analysis of the genome itself.

\section{ACKNOWLEDGMENTS}

We wish to thank Ms. Leslie Merritt, Mr. Joseph Gardner, and Ms. Julia A. Metcalf for their assistance. We are indebted to Dr. Michael F. Parry for providing MPO-deficient cells for our study, Dr. Ed Snyder of the Yale-New Haven Hospital Blood Bank, and Dr. R. M. Kakaiya of the Connecticut Chapter of the American Red Cross for kindly supplying us with outdated leukocytes prepared for transfusion, and to Ms. Lil Chapman for diligence and patience in preparing this manuscript.

This work was supported by U.S. Public Health Service grants AI 15252, AI 18166, and National Foundation Clinical Research grant 6-269 to Dr. Malech, George A. Carden fellowship gifts to Dr. Malech and Dr. Nauseef, a BurroughsWellcome fellowship grant to Dr. Nauseef and U.S. Public Health Service grants AI 13251, AI 07033, and a gift from the Technicon Corporation to Dr. Root.

\section{REFERENCES}

1. Schultz, J. 1980. Myeloperoxidase. In The Reticuloendothelial System: A Comprehensive Treatise. V. 2. Biochemistry and Metabolism. A. J. Sbarra, and R. R. Strauss, editors. Plenum Press, New York. 231-254.

2. Klebanoff, S. J. 1967. Iodination of bacteria: a bactericidal mechanism. J. Exp. Med. 126: 1063-1078.

3. Klebanoff, S. J., and C. B. Harmon. 1972. Role of myeloperoxidase-mediated antimicrobial systems in intact leukocytes. J. Reticuloendothel. Soc. 12: 170-196.

4. Klebanoff, S. J. 1970. Myeloperoxidase: contribution to the microbicidal activity of intact leukocytes. Science (Wash. DC). 169: 1095-1097.

5. McRipley, R. J., and A. J. Sbarra. 1967. Role of the phagocyte in host-parasite interaction. XII. Hydrogen peroxide-myeloperoxidase bactericidal system in the phagocyte. J. Bacteriol. 94: 1425-1430.

6. Root, R. K., and M. S. Cohen. 1981. The microbicidal mechanisms of human neutrophils and eosinophils. Rev. Infect. Dis. 3: 565-598.

7. Grignaschi, V. J., A. M. Sperperato, M. J. Etcheverry, and A. J. L. Macario. 1963. An nuevo cuadio eitoguimico: negativad espontanea de las reacciones de peroxidisas, oxidas y lipido en la progenia. Rev. Asoc. Med. Argent. 77: 218-221.

8. Undritz, E. 1966. Die Alius-Grignaschi-Anomalie: der erblich kunstitutionelle Peroxydasedefekt der Neutrophilen und Monozyten. Blut. 14: 129-136.

9. Lehrer, R. I., and M. J. Cline. 1969. Leukocyte myeloperoxidase deficiency and disseminated candidiasis: the role of myeloperoxidase in resistance to Candida infection. J. Clin. Invest. 48: 1478-1488.

10. Salmon, S. E., M. J. Cline, J. Schultz, and R. I. Lehrer. 1970. Myeloperoxidase deficiency. Immunologic study of a genetic leukocyte defect. N. Engl. J. Med. 282: 250253.

11. Moosmann, K., and A. Bojanovsky. 1975. Rezidivierende candidasis bei myeloperoxydasemangel. Mschr. Kinderheilk. 123: 408-409.

12. Rosen, H., and S. J. Klebanoff. 1976. Chemiluminescence and superoxide production by myeloperoxidasedeficient leukocytes. J. Clin. Invest. 58: 50-60.
13. Huhn, D., B. H. Belohradsky, and R. Hass. 1978. Familiarer myeloperoxidas-defekt und akute myeloische leukamie. Acta Haematol. 59: 129-143.

14. Cech, P., H. S. Stalder, J. J. Widmann, A. Rohrer, and P. A. Miescher. 1979. Leukocyte myeloperoxidase deficiency and diabetes mellitus associated with Candida albicans liver abscess. Am. J. Med. 66: 149-153.

15. Kitahara, M., H. J. Eyre, Y. Simonian, C. L. Atkin, and S. J. Hasstedt. 1981. Hereditary myeloperoxidase deficiency. Blood. 57: 888-893.

16. Parry, M. F., R. K. Root, J. A. Metcalf, K. K. Delaney, L. S. Kaplow, and W. J. Richar. 1981. Myeloperoxidase deficiency. Prevalence and clinical significance. Ann. Intern. Med. 95: 293-301.

17. Verdot, J. J., J. Boyle, I. Julan, M. F. Aillaud, A. M. Guitard, and R. Muratore. 1981. Hemogramme automatise et deficit en myeloperoxidase. Analyse de trentetrois observations. Sem. Hop. Paris. 57: 450-457.

18. Higashi, O., N. Katsoyama, and R. Satodate. 1965. A case with hematological abnormality characterized by the absence of peroxidase activity in blood polymorphonuclear leukocytes. Tohoku J. Exp. Med. 87: 77-93.

19. Davis, A. T., R. D. Brunning, and P. G. Quie. 1971. Polymorphonuclear leukocyte myeloperoxidase deficiency in a patient with myelomonocytic leukemia. $N$. Engl. J. Med. 285: 789-790.

20. Catovsky, D., D. A. G. Galton, and J. Robinson. 1972. Myeloperoxidase-deficient neutrophils in acute myeloid leukemia. Scand. J. Haematol. 9: 142-148.

21. Lehrer, R. I., L. S., Goldberg, M. A. Apple, and N. P. Rosenthal. 1972. Refractory megaloblastic anemia with myeloperoxidase-deficient neutrophils. Ann. Intern. Med. 76: 447-453.

22. Cech, P., A. Papathanassiou, G. Boreux, P. Roth, and P. A. Miescher. 1979. Hereditary myeloperoxidase deficiency. Blood. 53: 403-411.

23. Agner, K. 1941. Verdoperoxidase: a ferment isolated from leukocytes. Acta Physiol. Scand. 2(Suppl. 8): 1-62.

24. Andrews, P. C., and N. I. Krinsky. 1981. The reductive cleavage of myeloperoxidase in half, producing enzymically active hemi-myeloperoxidase. J. Biol. Chem. 256: 4211-4218.

25. Clift, R. A., J. E. Sanders, E. D. Thomas, B. Williams, and C. D. Buckner. 1978. Granulocyte transfusions for the prevention of infection in patients receiving bone marrow transplants. N. Engl. J. Med. 298: 1052-1057.

26. Amrein, P. C., and T. P. Stossel. 1980. Prevention of degradation of human polymorphonuclear leukocyte protein by diisopropylfluorophosphate. Blood. 56: 442447.

27. Klempner, M. S., R. B. Mikkelsen, D. H. Corfman, and J. Andre-Schwartz. 1980. Neutrophil plasma membranes. 1. High-yield purification of human neutrophil plasma membranes vesicles by nitrogen cavitation and differential centrifugation. J. Cell Biol. 86: 21-28.

28. Agner, K. 1958. Crystalline myeloperoxidase. Acta Chem. Scand. 12: 89-94.

29. Bakkenist, A. R. J., R. Wever, T. Volsma, H. Plat, and B. F. Van Gelder. 1979. Isolation procedure and some properties of myeloperoxidase from human leukocytes. Biochim. Biophys. Acta. 524: 45-54.

30. Reisfeld, R. A., U. J. Lewis, and D. E. Williams. 1962. Disk electrophoresis of basic proteins and peptides in polyacrylamide gels. Nature (Lond.). 195: 281-283.

31. Laemmli, U. K. 1970. Cleavage of structural proteins 
during the assembly of the head of bacteriophage T4. Nature (Lond.). 227: 680-685.

32. Towbin, H., T. Staehelin, and J. Gordon. 1979. Electrophoretic transfer of proteins from polyacrylamide gels to nitrocellulose sheets: procedure and some applications. Proc. Natl. Acad. Sci. USA. 76: 4350-4354.

33. Graham, R. C., and M. J. Karnovsky. 1966. The early stages of absorption of injected horseradish peroxidase in the proximal tubules of mouse kidney: ultrastructural cytochemistry by a new technique. J. Histochem. Cytochem. 14: 291-302.

34. Matheson, N. R., P. S. Wong, and J. Travis. 1981. Isolation and properties of human neutrophil myeloperoxidase. Biochemistry. 20: 325-330.
35. Sedmak, J. J., and S. E. Grossberg. 1977. A rapid, sensitive, and versatile assay for protein using Coomassie Brilliant Blue G250. Anal. Biochem. 79: 544-552.

36. Harrison, J. E., S. Pabalan, and J. Schultz. 1977. The subunit structure of crystalline canine myeloperoxidase. Biochim. Biophys. Acta. 493: 247-259.

37. Olsson, I., T. Olofsson, and H. Odeberg. 1972. Myeloperoxidase-mediated iodination in granulocytes. Scand. J. Haematol. 9: 483-491.

38. Yamada, M., M. Midori, and T. Sugimura. 1981. Purification and characterization of small molecular weight myeloperoxidase from human promyelocytic leukemia HL-60 cells. Biochemistry. 20: 766-771. 